\title{
SENAM KAKI DIABETIK SEBAGAI UPAYA PENINGKATAN SELF CARE PADA PASIEN DIABETES MELLITUS DI RUMAH SAKIT MARDIRAHAYU KUDUS
}

\author{
Devi Setya Putri ${ }^{1}$, Erlangga Galih Zulva Nugroho ${ }^{2}$ \\ Program Studi IImu Keperawatan STIKES Cendekia Utama Kudus \\ depisetyaputri@gmail.com
}

\begin{abstract}
ABSTRAK
Diabetes Mellitus (DM) yang berlangsung dalam waktu yang lama dan terus menerus dapat mengganggu kualitas hidup penderita. Penurunan kualitas hidup pada pasien diabetes mellitus sering diikuti dengan ketidaksanggupan pasien tersebut dalam melakukan perawatan diri secara mandiri yang biasanya disebut dengan self care. Ketidaksanggupan pasien diabetes mellitus dalam melakukan self care dapat mempengaruhi kualitas hidup dari segi kesehatan fisik, kesejahteraan psikologis, hubungan social, dan hubungan lingkungan. Self care yang dilakukan pada penderita diabetes mellitus lebih dititik beratkan pada pencegahan komplikasi dan pengontrolan gula darah. Salah satu tindakan self care pada pasien DM adalah olahraga atau latihan fisik. Berolahraga secara teratur dapat menurunkan dan menjaga kadar gula darah tetap normal. Dimana salah satu foot exercise untuk pasien diabetes mellitus adalah senam kaki diabetic. Metode pengabdian masyarakat ini adalah observasional analitik menggunakan sampel sebanyak 30 pasien DM di RS Mardirahayu Kudus. Pengabdian masyarakat ini dilakukan pada bulan Februari 2020. Pemilihan sampel dilakukan berdasarkan total sampling. Teknik pengambilan data primer dilakukan melalui pengukuran self care menggunakan kuesioner Summary of Diabetes Self-Care Activities (SDSCA). Hasil kegiatan senam kaki diabetic pada pasien DM sebelum dilakukan senam kaki self care kurang $60 \%$, baik $40 \%$, dan setelah dilakukan senam kaki diabetic self care kurang $30 \%$, baik $70 \%$.
\end{abstract}

Kata kunci : Senam Kaki Diabetik, Self Care, Diabetes Mellitus

\section{ABSTRACT}

Diabetes Mellitus (DM) which lasts for a long time and continuously can disrupt the quality of life of sufferers. Decreased quality of life in patients with diabetes mellitus is often followed by the inability of these patients to perform self-care independently, which is usually called self care. The inability of patients with diabetes mellitus to perform self care can affect the quality of life in terms of physical health, psychological well-being, social relations, and environmental relations. Self care that is done in people with diabetes mellitus is more focused on preventing complications and controlling blood sugar. One of the self care actions in DM patients is exercise or physical exercise. Exercising regularly can reduce and maintain blood sugar levels remain normal. Where one of the foot exercises for patients with diabetes mellitus is diabetic foot exercises. The method of community service is observational analytic using a sample of $30 \mathrm{DM}$ 
patients at Mardirahayu Kudus Hospital. This community service was conducted in February 2020. The sample selection was done based on total sampling. The primary data collection technique was carried out through self care measurement using questionnaire. The results of diabetic foot exercises activities in DM patients before self care foot exercises are less 60\%, 40\% good, and after doing diabetic foot exercises less 30\%, good $70 \%$.

Keywords: Diabetic Foot Exercises, Self Care, Diabetes Mellitus 


\section{PENDAHULUAN}

Indonesia saat ini menduduki rangking keempat dengan jumlah penyandang diabetes terbanyak setelah Amerika Serikat, China dan India. Menurut riset kesehatan dasar (Riskesdas) 2013 penderita diabetes mellitus mengalami peningkatan di seluruh provinsi di Indonesia termasuk di Jawa Tengah [1].

Berbagai keluhan terkait DM yang berlangsung dalam waktu yang lama dan terus menerus dapat mengganggu kualitas hidup penderita[1]. Kualitas hidup penderita DM dipengaruhi oleh beberapa faktor diantaranya yaitu lama menderita DM dan komplikasi DM $[1,3]$. Hal ini sejalan dengan hasil penelitian Irdayana, dimana hasil penelitian menunjukkan bahwa pengelolaan diabetes, lama menderita, dan komplikasi berhubungan dengan kualitas hidup pasien DM [4].

Terdapat beberapa aspek yang dapat mempengaruhi kualitas hidup, aspek tersebut adalah adanya kebutuhan khusus yang terus menerus berkelanjutan dalam perawatan DM, gejala apa saja yang kemungkinan muncul ketika kadar gula darah tidak stabil, komplikasi yang dapat timbul akibat dari penyakit diabetes.[5] Aspek tersebut dapat dicegah apabila pasien tersebut dapat melakukan pengontrolan yang baik dan teratur. Sehingga tidak terjadi komplikasi yang dapat menurunkan kualitas hidup pasien diabetes mellitus dan dapat menjalankan kehidupan sehariharinya.[9]

Penurunan kualitas hidup pada pasien diabetes mellitus sering diikuti dengan ketidaksanggupan pasien tersebut dalam melakukan perawatan diri secara mandiri yang biasanya disebut dengan self care. Ketidaksanggupan pasien diabetes mellitus dalam melakukan self care dapat mempengaruhi kualitas hidup dari segi kesehatan fisik, kesejahteraan psikologis, hubungan social, dan hubungan lingkungan. Self care yang dilakukan pada penderita diabetes mellitus lebih dititik beratkan pada pencegahan komplikasi dan pengontrolan gula darah. Apabila self care dilakukan dengan baik maka secara tidak langsung 
dapat meningkatkan kualitas hidup pasien diabetes mellitus sehingga dapat menjalankan aktifitas sehari-hari dengan normal.[11]

Self care yang dilakukan pada pasien diabetes mellitus meliputi pengaturan pola makan (diet), pemantauan kadar gula darah, terapi obat, perawatan kaki, dan latihan fisik (olahraga). Salah satu tindakan self care pada pasien DM adalah olahraga atau latihan fisik. Berolahraga secara teratur dapat menurunkan dan menjaga kadar gula darah tetap normal.[6] Dimana salah satu foot exercise untuk pasien diabetes mellitus adalah senam kaki diabetic.[9] Hal ini sejalan dengan hasil penelitian yang dilakukan oleh Santosa dan Rusmono, senam kaki pada pasien diabetes mellitus dengan signifikan dapat menurunkan kadar gula darah sewaktu sejak pertama kali treatment.[10] Dengan olahraga, akan memperbanyak jumlah dan meningkatkan aktivitas reseptor insulin dalam tubuh dan juga meningkatkan penggunaan glukosa [7].

Peneliti memilih senam kaki diabetik sebagai penatalaksanaan pada pasien DM, sebagai upaya atau tindakan untuk perawatan secara mandiri pada pasien DM, sehingga diharapkan mencegah terjadinya komplikasi pada pasien DM serta kadar gula darah pasien terkontrol.[8] Dengan peningkatan self care pada pasien DM, dapat terjadi peningkatan kualitas hidup pada pasien DM.[2]

Berdasarkan uraian latar belakang masalah diatas, maka perlu dilakukan pengabdian masyarakat senam kaki diabetic sebagai upaya peningkatan self care pada pasien DM di Rumah Sakit Mardirahayu Kudus.

\section{METODE PELAKSANAAN}

Metode yang digunakan dalam pengabdian masyarakat ini adalah observasional analitik menggunakan sampel sebanyak 30 pasien DM yang dirawat di RS Mardirahayu Kudus. Pemilihan sampel dilakukan berdasarkan total sampling. Tehnik pengambilan data primer dilakukan 
melalui pengukuran self care senam kaki diabetic menggunakan kuesioner.

Self care yang dilakukan pada pasien diabetes mellitus meliputi pengaturan pola makan (diet), pemantauan kadar gula darah, terapi obat, perawatan kaki, dan latihan fisik (olahraga). Dalam pengabdian masyarakat ini, self care yang dilakukan berupa latihan fisik yang bertujuan untuk meningkatkan kadar sensitivitas reseptor insulin sehingga dapat beraktivitas dengan baik. Salah satu latihan aktivitas untuk pasien diabetes mellitus adalah Senam Kaki Diabetik. Senam Kaki Diabetik yang dilakukan oleh pasien DM lebih mengutamakan pengontrolan gula darah dan pencegahan komplikasi sehingga self care sangat penting bagi pasien diabetes mellitus.

\section{HASIL DAN PEMBAHASAN}

Pengabdian masyarakat ini dilakukan di Rumah Sakit Mardirahayu Kudus. Responden yang menjadi subjek penelitian ini adalah sebanyak 30 responden yang telah memenuhi kriteria dalam penelitian ini. Hasil penelitian meliputi karakteristik responden, self care sebelum dan sesudah senam kaki diabetik, serta analisa perbedaan self care antara sebelum dan setelah diberikan senam kaki diabetik.

Sasaran pada pengabdian masyarakat ini adalah pasien diabetes mellitus di RS Mardirahayu Kudus. Dalam pengabdian masyarakat ini sampel berjumlah 30 responden.

Hasil perubahan self care senam kaki diabetic pada pasien diabetes mellitus di Rumah Sakit Mardirahayu Kudus, dijabarkan dalam table berikut :

Tabel 1. Hasil Perubahan Self Care Senam Kaki Diabetic

\begin{tabular}{ccccc}
\hline Self Care & \multicolumn{2}{c}{ Sebelum } & \multicolumn{2}{c}{ Sesudah } \\
\hline & Frekuensi & Persentase (\%) & Frekuensi & Persentase (\%) \\
\hline Kurang & 18 & $60 \%$ & 9 & $30 \%$ \\
Baik & 12 & $40 \%$ & 21 & $70 \%$ \\
Total & & & & \\
\hline
\end{tabular}


Berdasarkan table tersebut diketahui bahwa hasil kegiatan senam kaki diabetic pada pasien DM di RS Mardirahayu sebelum diberikan senam kaki diabetic self care kurang sebanyak (60\%), baik (40\%), dan setelah dilakukan senam kaki diabetic self care kurang sebanyak $(30 \%)$, dan baik sebanyak (70\%).

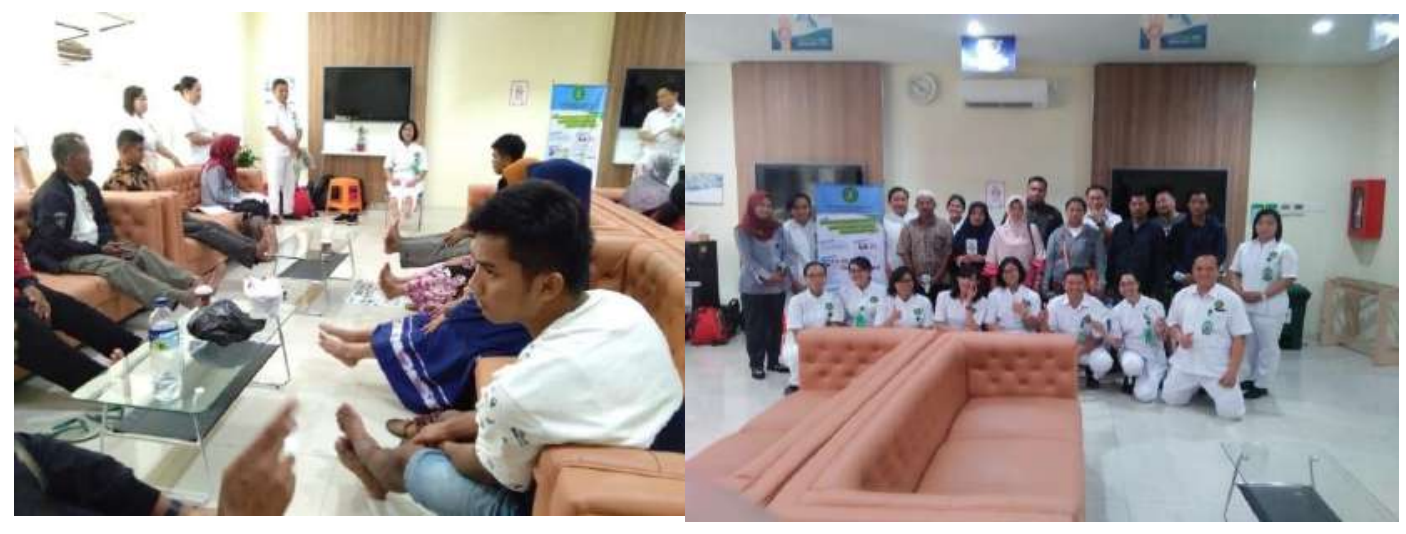

Gambar 1 : senam kaki diabetik di Rumah Sakit Mardirahayu Kudus

Setiap melakukan olahraga dapat meningkatkan laju jantung, tekanan darah dan kontraktilitas miokard dan temuan klinis setelah melakukan olahraga 60 menit dapat meningkatkan vasodilatasi di arteri. Olahraga dapat berpengaruh pada dinding pembuluh darah berupa peningkatan pertahan antioksidan (menurunkan oksidatif stress), meningkatkan kemampuan Nitric Oxcide (NO), terjadinya peningkatan tekanan pada arteri dapat menyebabkan pelebaran pada dinding arteri dan tekanan pembuluh darah perifer.

Senam kaki dilakukan dengan gerakan slowstrech-hold yang memungkinkan penderita untuk menggunakan beban berat badan sebagai body-weightbearing yang dimulai dengan gerakan yang pelan kemudian dengan kekuatan ototnya gerakan tersebut semakin ditingkatkan dan diakhiri dengan gerakan penahanan posisi.

Intervensi senam kaki, merupakan aplikasi tindakan keperawatan berupa Exercise promoting: Stretching (Bulechek et al, 2013) yang dilakukan secara sistematik dan teratur dengan gerakan slow-strech-hold bertujuan untuk meningkatkan kekuatan otot. Dalam melakukan gerakan 
senam kaki selama 15 - 20 menit sel-sel otot kaki membutuhkan energi berupa suplai darah yang berasal dari jantung disalurkan melalui arteri femoralis menunju ke poplitea dan dorsalis pedis. Keadaan tersebut terlihat jelas dengan adanya kenaikan nadi setelah treatment senam kaki 4 - $10 \mathrm{kali} / \mathrm{menit}$, menunjukkan bahwa jantung dalam hal ini sebagai sirkulasi sentral telah memberikan tambahan energi bagi sel-sel otot yang digunakan pada saat senam kaki, juga didukung dengan peningkatan tekanan sistolik setelah treatment senam kaki $5-10 \mathrm{mmHg}$.

Senam kaki merupakan gerakan untuk melatih otot kecil kaki dan memperbaiki sirkulasi darah yang dilakukan dalam berbagai posisi seperti duduk, berdiri maupun tiduran dengan tujuan untuk meningkatkan pemulihan dan mengembalikan kapasitas kerja otot mempercepat penyembuhan luka, dan meningkatan kepadatan volume mitokondria dan kapasitas oksidatif pada jaringan otot kaki, ekstraksi oksigen perifer, vasodilator perifer, kapasitas otot, curah jantung, penurunan kejadian restenosis dan tekanan akhir diastolic.

Maka diperlukan senam kaki yang dilakukan secara kontinyu dan sistematis setiap harinya, hal ini dikarenakan efek dari senam kaki tersebut dapat meningkatkan sensitifitas sel terhadap insulin sehingga gula darah akan masuk ke sel untuk dilakukan proses metabolisme. Program olah raga berintensitas memberikan berbagai efek yang bermanfaat, termasusk peningkatan sensitifitas insulin dan perbaikan pengendalian glikemia sehingga manifestasi komplikasi kaki tidak terjadi.

Hal ini sejalan dengan hasil penelitian yang dilakukan oleh Santoso, bahwa sebelum dan sesudah dilakukan senam kaki diperoleh hasil terdapat penurunan gula darah sewaktu yang signifikan setelah dilakukan senam kaki pada pasien dengan diabetes mellitus baik pada treatment I sampai treatment ke IV.

Dengan melakukan senam kaki maka manifestasi komplikasi tidak terjadi, diharapkan dengan secara mandiri melakukan senam kaki maka kadar gula darah pasien DM terkendali, sehingga dapat tercapai kualitas 
hidup yang baik bagi pasien DM. Hal ini sejalan dengan hasil penelitian yang dilakukan oleh Chaidir, Wahyuni, dan Furkhani (2020), hasil penelitian bahwa terdapat hubungan antara self care dengan kualitas hidup pasien diabetes mellitus di wilayah kerja Puskesmas Tigo Baleh. Pasien DM diharapkan meningkatkan aktivitas self care sehingga dapay mencapai kualitas hidup yang baik.

\section{SIMPULAN DAN SARAN}

Kegiatan pengabdian masyarakat ini berupa Senam Kaki Diabetik terhadap Self Care Pada Pasien DM di RS Mardirahayu Kudus. Senam Kaki Diabetik ini merupakan salah satu bentuk upaya peningkatan perawatan diri secara mandiri pada pasien DM. Diharapkan pasien secara mandiri akan melakukan tindakan senam kaki diabetic, sehingga komplikasi dapat dicegah serta kadar gula darah pasien dapat terkontrol. Upaya self care melalui senam kaki diabetic pada pasien DM merupakan salah satu dari upaya self care latihan fisik. Dengan melakukan self care senam kaki diabetic yang baik pada pasien DM, maka kualitas hidup yang baik pada pasien DM akan tercapai baik dari segi fisik, hubungan social, psikologis, maupun hubungan lingkungan.

\section{UCAPAN TERIMAKASIH}

1. Program Pengabdian masyarakat ini dibiayai oleh STIKES Cendekia Utama Kudus dengan Surat Perjanjian Kontrak Pengabdian Masyarakat (SPK-PM) Nomor: 027/SK-PI/LPPM-STIKES CU///2020 Tanggal 13 Januari 2020.

2. Direktur RS Mardirahayu Kudus Bapak Pujianto yang telah memberikan ijin sehingga program pengabdian masyarakat ini berjalan dengan baik dan lancar. 


\section{DAFTAR PUSTAKA}

1. Nasekhah, A.D. (2016). Hubungan Kelelahan Dengan Kualitas Hidup Penderita Diabetes Melitus Tipe 2 Di Persadia Salatiga. Universitas Diponegoro

2. Azila, A.A. (2016). Gambaran Kualitas Hidup Pasien Diabetes Mellitus Tipe 2 Di Poli Interna RSD dr. Soebandi Jember. Universitas Jember

3. Irdayana, dkk. (2015). Kualitas Hidup Pasien Diabtes Mellitus Tipe 2 Di Rumah Sakit Tk. II Pelamonia Makassar

4. Sundaralingam, T. (2015). Gambaran Risiko Penderita Diabetes Mellitus Di Puskesmas Padang Bulan.Universitas Sumatera Utara

5. Setiyorini, E. (2017). Hubungan Lama Menderita Dan Kejadian Komplikasi Dengan Kualitas Hidup Lansia Penderita Diabetes Mellitus Tipe 2. Universitas Muhammadiyah Magelang

6. Purwaningsih, N. (2018). Analisis Faktor-Faktor Yang Mempengaruhi Kualitas Hidup Pasien Diabetes Mellitus Tipe 2 Di Instalasi Rawat Jalan RSUD Dr. Moewardi Surakarta. Universitas Muhammadiyah Surakarta

7. Siwiutami, F. (2017). Gambaran Kualitas Hidup Pada Penyandang Diabetes Mellitus Di Wilayah Puskesmas Purwosari Surakarta. Universitas Muhammadiyah Surakarta

8. Darma, KK. (2011). Metodologi penelitian keperawatan: panduan melaksanakan dan menerapkan hasil penelitian. Jakarta: Trans Info Media.

9. Putri, Linda Riana. (2017). Gambaran Self Care Penderita Diabetes Mellitus (DM) Di Wilayah Kerja Puskesmas Srondol Semarang.

10. Santosa, Rusmono. (2016). Senam Kaki Untuk Mengendalikan Kadar Gula Darah dan Menurunkan Tekanan Brachial Pada Pasien Diabetes Mellitus.

11. Chaidir,Wahyuni, Furkhani. (2017). Hubungan Self Care Dengan Kualitas Hidup Pasien Diabetes Mellitus. 